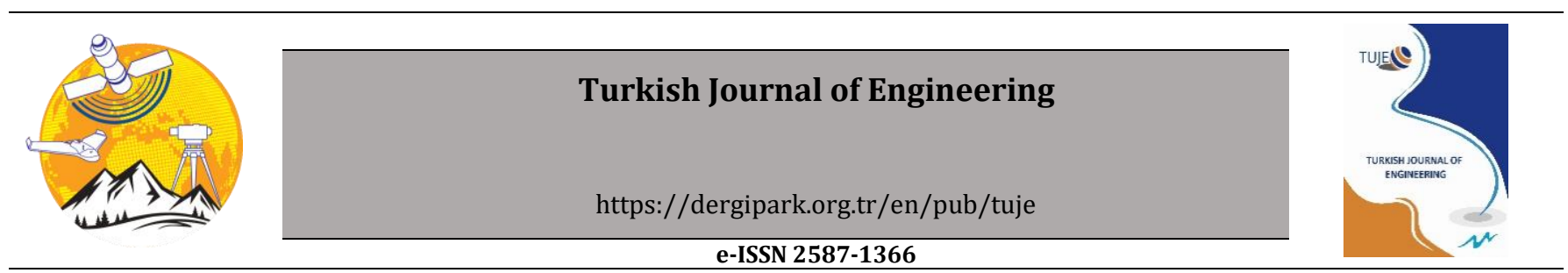

\title{
Investigation of high temperature effects in different mineral additive light mortars
}

\author{
Behcet Dündar *1 ${ }^{(D)}$, Emriye Çınar ${ }^{1}(\mathbb{D}$ \\ ${ }^{1}$ Osmaniye Korkut Ata University, Engineering Faculty, Civil Engineering Department, Osmaniye, Turkey
}

\author{
Keywords \\ Light mortar \\ Pumice \\ Mineral additive \\ High temperature
}

\begin{abstract}
In this study, physical and mechanical properties of light mortars produced with Fly Ash (FA) contributed pumice aggregates, Colemanite (K), Blast Furnace Slag (BFS), Marble powder (MP) were investigated under high temperature. Mortar samples were produced in the dimensions of $40 \times 40 \times 160 \mathrm{~mm}$. At the preparation of mortars, pumice $(0-4 \mathrm{~mm})$ as a fine aggregate and CEM I 42.5R Portland Cement were replaced with. $1 \%, 2 \%$ and $3 \%$ by weight of K respectively and $10 \%, 20 \%$ and $30 \%$ of YFC, MT and UK were replaced with cement in light mortars mixture. The produced mortar samples were removed from the mold after 24-hour setting and subjected to a cure at a temperature of $20 \pm 2^{\circ} \mathrm{C}$ in the standard cure pool for 28 days. The flexural and compressive strength of the mortar samples filling the 7 th day were determined. Physical properties such as water absorption, porosity and unit volume weight of 28 days cured mortars were determined and flexural and compressive strengths were calculated. At the end of 28th day samples, which were reached its final strength, were exposed to $200{ }^{\circ} \mathrm{C}, 400{ }^{\circ} \mathrm{C}, 600{ }^{\circ} \mathrm{C}$ and $800{ }^{\circ} \mathrm{C}$ heats in High Temperature Oven. It is observed that with increasing temperature, weight loss increases, flexural and compressive strengths decrease in all samples. With the use of mineral additives, it was observed that both the weight losses and the losses in flexural and compressive strengths decreased and the mortars became more resistant to temperature.
\end{abstract}

\section{INTRODUCTION}

As a result of population growth and land restriction, the need for high-rise buildings and underground constructions is rapidly increasing to solve housing and transportation problems effectively. In such civil engineering structures, it is faced that large amounts of fire damage during construction and service. It is known that fires, which are frequently encountered worldwide in recent years, seriously threaten personal and property security. It is known that high temperature causes a decrease in the mechanical strength of the concrete and creates harmful effects at the structural level due to the high temperature exposure of the reinforcement (Seshu and Pratusha 2013; Heikal et al. 2013).

The effect of high temperature on the strength of mortar and concrete is generally grouped as material and environmental factors. Material factors include aggregate, aggregate-cement paste interface, thermal mismatch of composite components and properties of cement paste (Khaliq et al. 2015). On the other hand, environmental factors include heating speed, exposure time to maximum temperature, cooling rate, loading conditions and humidity, which are important when examining the behavior of mortar and concrete samples at high temperatures. Previous studies have shown that the strength and elasticity module of cement-based mortar and concrete samples decrease with the increase in temperature (Li et al. 2018; Pan et al. 2018).

It is the decomposition of hydration products that cause concrete to lead to loss of strength at high temperatures. The researchers stated that the decomposition of the cementitious matrix started above $105^{\circ} \mathrm{C}$. The first step of chemical and physical decomposition is to release the water in the pores and chemically bound water in the structure of calcium silicate hydrate (C-S-H) gels (Arioz 2007). At this step, other hydrates and ettringite also begin to decompose. Also, aggregate may start to be affected according to its origin and type (Gawin et al. 2004). Approximately 300$400{ }^{\circ} \mathrm{C}$, chemically bound intermediate layer water in the $\mathrm{C}-\mathrm{S}-\mathrm{H}$ gel evaporates. Also, the first microcracks begin to appear in the $\mathrm{Ca}(\mathrm{OH})_{2}$ and anhydrite cement areas. At this stage, $\mathrm{Ca}(\mathrm{OH})_{2}$ decomposes into $\mathrm{CaO}$ and $\mathrm{H}_{2} \mathrm{O}$. However, in the cooling process, $\mathrm{CaO}$ can rehydrate to $\mathrm{Ca}(\mathrm{OH})_{2}$, and this rehydration creates a significant 
volume expansion of about 44\%. This volumetric expansion increases the number of cracks. It is known that the use of mineral additives in cement based materials consumes $\mathrm{Ca}(\mathrm{OH})_{2}$ (Lin et al. 1996; Mendes et al. 2011).

However, in recent years, interest in consuming substitute materials such as solid wastes in the construction industry has increased steadily. The consumption of waste materials is compatible with basic environmental approaches in terms of preventing waste, reusing waste materials, reducing storage areas, reducing energy from waste and saving natural resources (Dimitriou et al. 2018; Juan-Vandes et al. 2018).

Although alternative materials such as wastes are used in many application areas, their technical characteristics, financial aspects and environmental effects should be taken into consideration. In the construction industry, the idea of sustainability and green production promotes the use of various waste materials instead of raw materials such as cement and aggregates (Tam et al. 2018; Huseien et al. 2019). Therefore, it leads to the production of an environmentally friendly structure with the use of waste materials (Mohammadhosseini et al. 2018).

Portland cement is the most widely used binder in the construction industry. On the other hand, Portland cement consumption has been discussed for many years due to approximately 1.5 billion tons of $\mathrm{CO}_{2}$ emission per year and $36 \%$ of global energy consumption (Andrew 2018; Kermeli et al. 2019).

Many researches are conducted on both fire resistance and the evaluation of waste products. In recent years, mineral additives have been used in mixtures to provide high temperature resistance. Among them, fly ash, blast furnace slag and silica fume are the most common (Akca and Özyurt 2018; Liang et al. 2018).

The effects of high temperature on the hardened properties of blended mortars containing pumice and fly ash powder were investigated. The produced mortars were exposed to $300{ }^{\circ} \mathrm{C}, 600{ }^{\circ} \mathrm{C}$ and $900{ }^{\circ} \mathrm{C}$ for 3 hours in mixtures containing $0 \%, 20 \%, 40 \%$ and $60 \%$ FA. Experimental results showed that pumice mortar containing $60 \%$ FA performs better, especially at $900{ }^{\circ} \mathrm{C}$ (Aydin and Baradan 2007).

In this study, the use of mineral additives was investigated in order to evaluate the waste products and to increase the durability of cement-based materials against the fire disaster that can be encountered today. In this context, $1 \%, 2 \%$ and $3 \%$ by weight of cement, $\mathrm{K}$, $10 \%, 20 \%$ and $30 \%$ of BFS, MP and FA were replaced by light mortars. After curing the mortar samples for 7 days, their mechanical properties such as flexural and compressive strengths were determined, and after 28 days of curing, their physical properties such as water absorption and porosity were determined. Mortar samples were exposed to 200, 400, 600 and $800{ }^{\circ} \mathrm{C}$ temperatures after 28 days. Weight losses, flexural and compressive strengths were determined after the applied heat.

\section{MATERIALS AND METHODS}

\subsection{Materials}

The cement, which is among the components of the mortar used in the production of test samples, is CEM I 42,5 R type cement produced in accordance with TS EN 197-1 (2012). Fly ash (FA), Blast Furnace Slag (BFS), Colemanite (K) and Marble Powder (MP) are used as mineral additives and their physical and chemical properties were given together cement in Table 1. Mineral additives were used by replacing with cement at the rates specified by weight. While mineral additives $\mathrm{K}$ were used at $1 \%, 2 \%, 3 \%$ rates, $\mathrm{BF}, \mathrm{AS}$ and $\mathrm{BF}$ were used at $10 \%, 20 \%, 30 \%$ rates. In the experimental study, city water of Osmaniye Province, which complies with TS EN 1008 was used (2003).

Pumice aggregate with 0-4 mm grain size was used in the mortar samples produced within the scope of the study. It contains numerous pores from macro scale to micro scale due to sudden cooling of the gases in the body and sudden cooling during pumice formation. It is light, can float in water for a long time, has low permeability and is highly insulated since it is generally interconnected between pores. Chemical content of silica can be up to $75 \%$. The $\mathrm{SiO}_{2}$ ratio of the rock gives the rock an abrasive feature. $\mathrm{Al}_{2} \mathrm{O}_{3}$ composition provides high resistance to fire and heat. Pumice deposits in Turkey, Urgup Avanos and Kayseri Talas- Tomarza-Develi and concentrated in Osmaniye (Yasar and Erdogan 2005). In this study, pumice aggregate, whose chemical properties are given in table 2 , which has the basic character obtained from Osmaniye Province, was used.

Table 1. Chemical and physical analysis results of CEM I 42,5 R Portland cement, fly ash (FA), Blast Furnace Slag (BFS), Colemanite (K) and Marble Powder (MP)

\begin{tabular}{lccccc}
\hline $\begin{array}{l}\text { Chemical } \\
\text { Analysis }\end{array}$ & $\begin{array}{c}\text { CEM I } \\
\text { 42,5/R }\end{array}$ & FA & BFS & $\mathrm{K}$ & $\mathrm{MP}$ \\
\hline $\mathrm{B}_{2} \mathrm{O}_{3}$ & - & - & & 39,85 & - \\
$\mathrm{SiO}_{2}$ & 19,33 & 47,4 & 32,8 & 5,60 & 4,67 \\
$\mathrm{Al}_{2} \mathrm{O}_{3}$ & 4,74 & 19,8 & 11,8 & 0,15 & 0,08 \\
$\mathrm{Fe}_{2} \mathrm{O}_{3}$ & 2,72 & 11,8 & 1,45 & 0,03 & 0,03 \\
$\mathrm{CaO}$ & 63,20 & 6,66 & 39,8 & 27,24 & 51,80 \\
$\mathrm{MgO}$ & 0,98 & 4,76 & 4,15 & 2,84 & 18,38 \\
$\mathrm{Na} 2 \mathrm{O}$ & 0,12 & 0,57 & 0,51 & 0,10 & 0,05 \\
Ignition Loss & 3,94 & 2,76 & 2,2 & 24,06 & 45,98 \\
Specific & & & & & \\
Surface & 3983 & 3126 & 4982 & 3839 & 6740 \\
(cm $/$ g) & & & & & \\
Specific & & & & & \\
Weight & 3,12 & 1,99 & 2,8 & 2,50 & 2,63 \\
(g/cm & & & & & \\
\hline
\end{tabular}

Table 2. Chemical analysis of basaltic pumice

\begin{tabular}{ll}
\hline Chemical Analysis & Pumice (\%) \\
\hline $\mathrm{SiO}_{2}$ & 45,95 \\
$\mathrm{Al}_{2} \mathrm{O}_{3}$ & 19,95 \\
$\mathrm{Fe}_{2} \mathrm{O}_{3}$ & 7,53 \\
$\mathrm{CaO}$ & 13,23 \\
$\mathrm{MgO}$ & 6,24 \\
$\mathrm{Na}_{2} 0+\mathrm{K}_{2} \mathrm{O}$ & 6,69 \\
Diğer & 0,41 \\
\hline Total & 100 \\
\hline
\end{tabular}




\subsection{Methods}

The amount of materials used in the samples produced in the experimental study are given in Table 3. Reference sample consists the mixture of pumice aggregate, cement and water. In other samples, FA, BFS, $\mathrm{K}$ and MP were used and the difference was observed. $10 \%, 20 \%, 30 \% \mathrm{FA}, \mathrm{BFS}, \mathrm{MP}$ and $1 \%, 2 \%, 3 \% \mathrm{~K}$ mineral additives were replaced by weight of cement. After making the mortar mixture, the lubricated molds were placed on the cement shaking table and the concrete mortar was poured into the molds in two stages. The mortar samples, which completed the set in the mold for 24 hours, were removed from the molds and cured in standard curing pools for 7 and 28 days. The flexural strength determination in accordance with TS EN 196-1 (2016) standard and compressive strength in accordance with TS EN 12390-4 (2002) were determined for the mortar samples filling the 7 th day. It was calculated in accordance with TS EN 1170-6 (1999) standard with the help of the Archimedes principle in order to determine the physical properties of the mortar samples filling the 28th day, such as water absorption and porosity. High temperature application was carried out in accordance with the principles specified in TS EN 13501-1 (2019) standard.

According to the standards, real fire occurs between 20-1000 ${ }^{\circ} \mathrm{C}$ and within 15-300 minutes. Mortar samples were applied at a temperature of $200{ }^{\circ} \mathrm{C}, 400{ }^{\circ} \mathrm{C}, 600{ }^{\circ} \mathrm{C}$ and $800^{\circ} \mathrm{C}$ with a temperature increase rate of $10{ }^{\circ} \mathrm{C} /$ min in a $1800{ }^{\circ} \mathrm{C}$ laboratory type oven and kept in the oven for 60 minutes at all temperatures. Then it was left to cool until it reached the temperature of the laboratory conditions. Samples subjected to high temperature, flexural, compressive tests and weight losses were determined after cooling.

\section{RESULTS AND DISCUSSION}

The water absorption (\%) values by weight of the mortar samples are given in Figure 1 and porosity (\%) values are given in Figure 2. A decrease in water absorption and porosity rates was observed in $30 \%$ of all mineral additives and in all ratios of $\mathrm{K}$. With the use of FA, water absorption and porosity values increased up to $20 \%$ compared to the reference sample, while its use decreased by $30 \%$. In the use of BFS, it was observed that the water absorption and porosity rates decreased with the increase of BFS rate and low water absorption and porosity values in all ratios compared to the reference sample. In case of using $1 \%$ and $3 \%$ of $\mathrm{K}$, water absorption and porosity values decrease according to the reference, while $2 \%$ increase has been observed. With the use of MP $10 \%$, water absorption and porosity values reached their highest value and a decrease was observed with the increase in the rate. The lowest water absorption value was obtained with the use of $30 \%$ BFS with the rate of $5.91 \%$ and the lowest water absorption with the ratio of $9.01 \%$ in mortars where $10 \%$ MP was used. The highest porosity value was obtained in mortars using $10 \%$ MP with a rate of $17,30 \%$, and the highest water absorption was achieved with the use of $30 \%$ BFS with a rate of $11,97 \%$. With the increase of mineral additives in the mortar, the amount of fine material increases. The need for water increases as the surface area increases with the increase of the fine substance. Settlement difficulties due to the need for water reveals difficulties and causes it to settle more porous, in this case, it causes an increase in water absorption and porosity values.

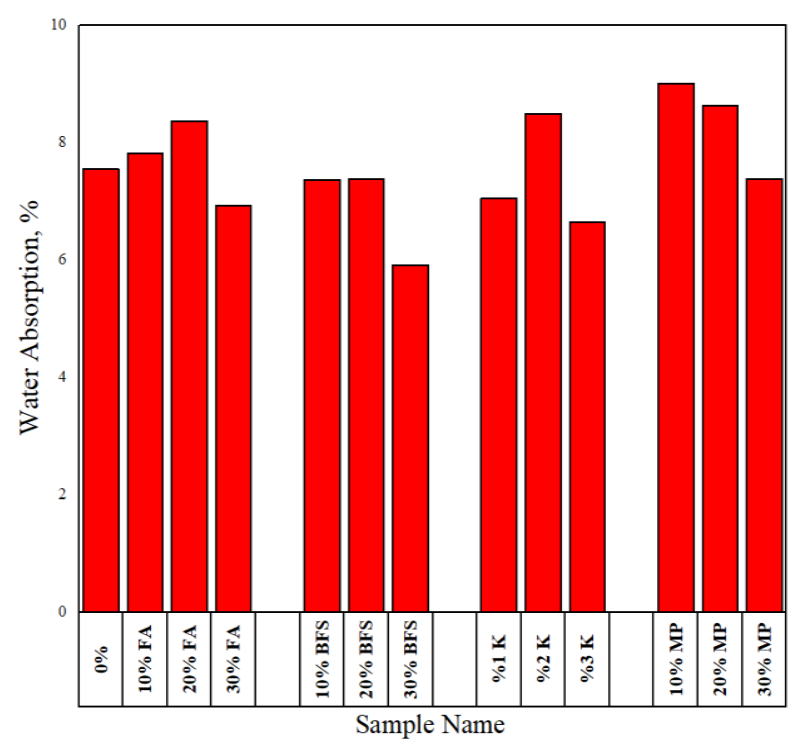

Figure 1. Water absorption values by weight (\%)

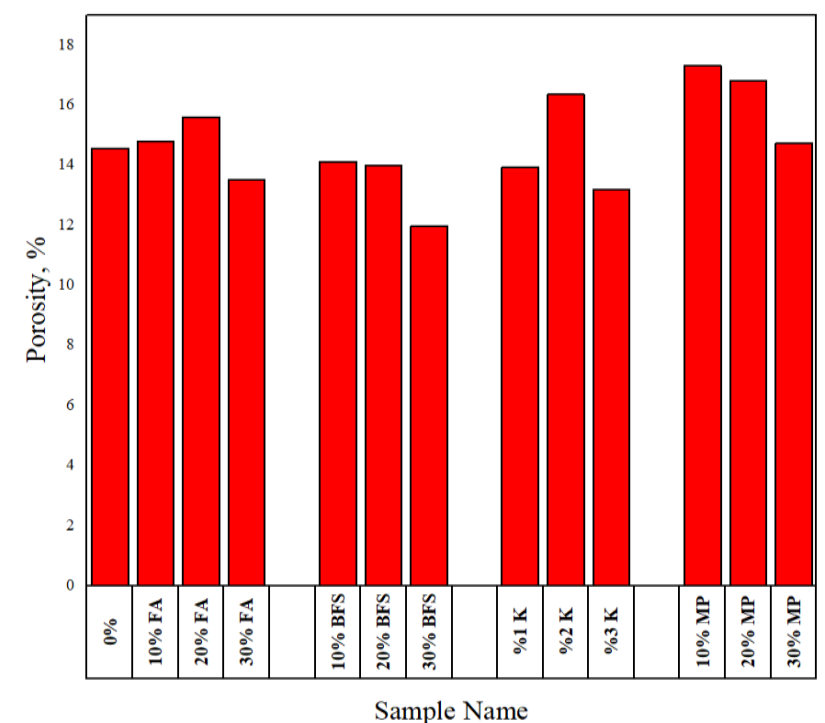

Figure 2. Porosity values by weight (\%)

The compressive strengths of the mortar samples are given in Figure 3 and the flexural strengths are given in Figure 4. A decrease in compressive strength was observed in all mineral additive types except for mortar samples used by $10 \%$ of MT. With the increase in the rate of mineral additives, there was a decrease in compressive strength in general. However, in case of rising the FA rate to $20 \%$, an increase in compressive strength is observed, while a $30 \%$ decrease is observed. 7-day compressive strength was observed in the reference sample with the highest $53.48 \mathrm{MPa}$, while the lowest with $39.93 \mathrm{MPa}$ in case of using $30 \%$ BFS. The 28-day compressive strength was observed in the sample using the highest $62.15 \mathrm{MPa}$ and 10\% MP, while the lowest $30.50 \mathrm{MPa}$ and 30\% MP were used. In case the rate of MP increased from $10 \%$ to 
$30 \%$, the compressive resistance decreased by approximately $50 \%$. A decrease in flexural strength was observed in all mineral additive types except MP and FA's $10 \%$ used mortar samples. With the increase in the ratio of mineral additives, there was a general decrease in flexural strength. 7-day flexural strength was observed in the samples with the highest 6,99 MPa and 10\% FA, while the lowest was $4.76 \mathrm{MPa}$ and 30\% MP. The 28-day flexural strength was observed in the sample with the highest $8.99 \mathrm{MPa}$ and $1 \% \mathrm{~K}$, while the lowest was 5.79 $\mathrm{MPa}$ and 30\% MP.

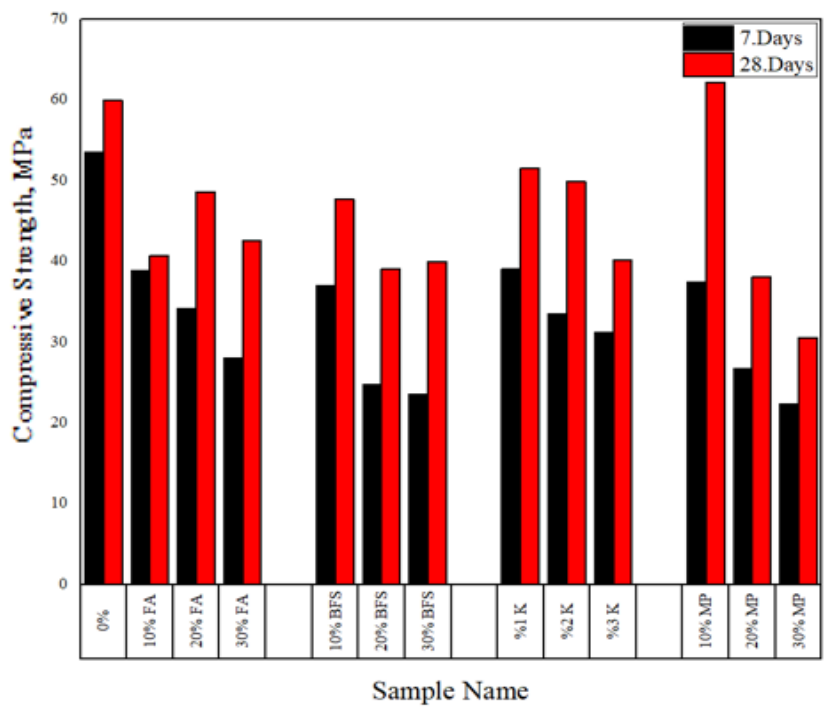

Figure 3. 7 and 28 days Compressive Strength of mortar samples

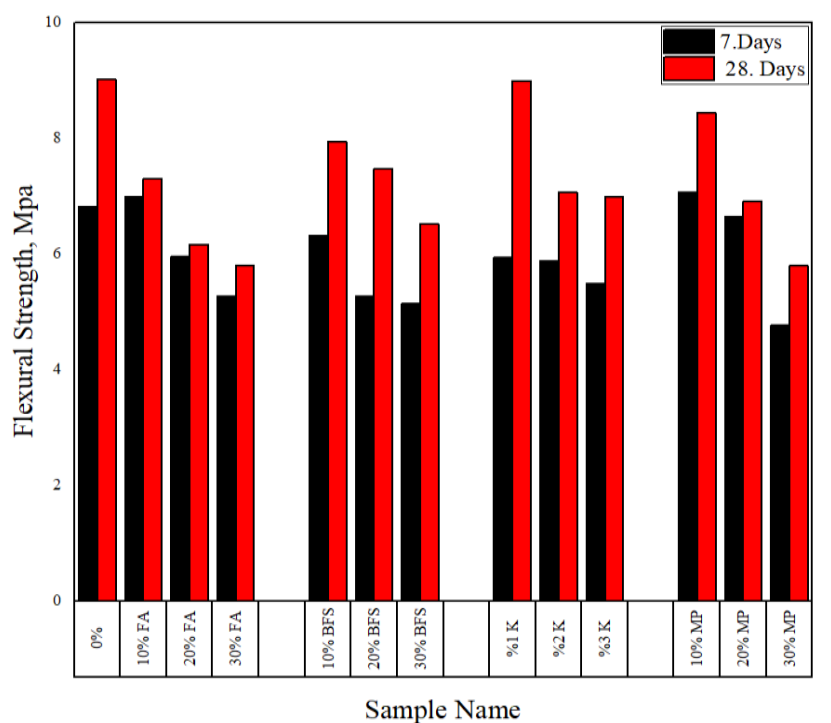

Figure 4. 7 and 28 days Flexural Strength of mortar samples

After applying high temperature, the weight losses of the samples were given in Figure 5 . With the increase in temperature, weight losses have increased. With the use of mineral additives, weight losses after high temperature are decreased. The reference sample showed a $2.78 \%$ weight loss in $200^{\circ} \mathrm{C}$, weight loss increased at $800^{\circ} \mathrm{C}$, which increased to $8.52 \%$. The lowest weight losses were observed in $200^{\circ} \mathrm{C}$ with a value of $1.14 \%$ for $10 \%$ MP-additive, $2.34 \%$ in $400^{\circ} \mathrm{C}$ and $30 \%$
$\mathrm{MPa}$ additive, $2.83 \%$ in $600^{\circ} \mathrm{C}$ and $3 \% \mathrm{~K}$ additive, $7.40 \%$ in $800^{\circ} \mathrm{C}$ and $30 \% \mathrm{MP}$ additive. The highest weight loss at all temperature values was seen in reference samples.

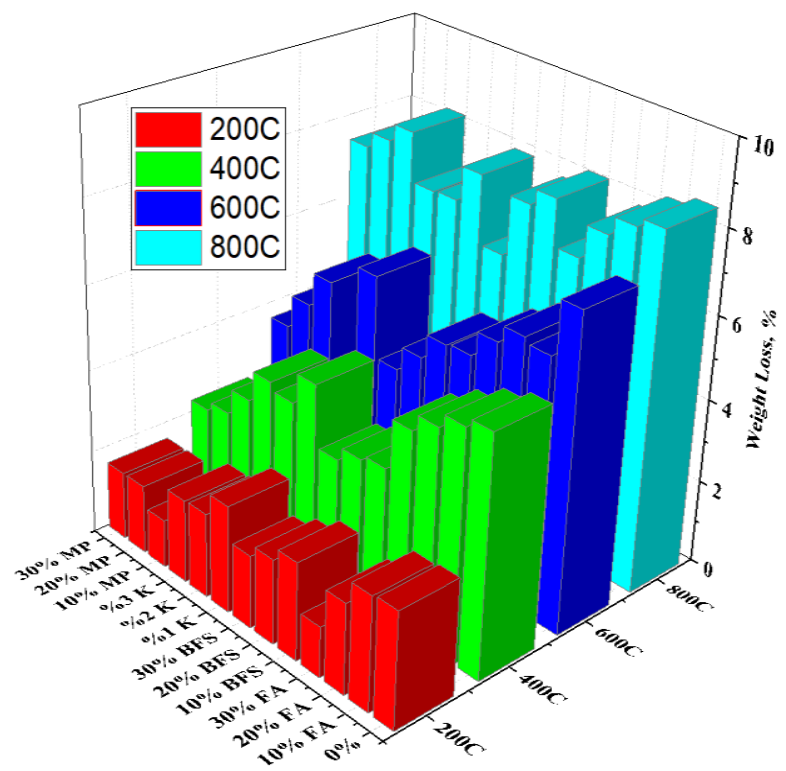

Figure 5. Weight loss before and after high temperature $(\%)$

Compressive strengths of 28 days samples before and after temperatures are given in Figure 6 and flexural strengths are given in Figure 7. Along with the increase in temperature, Compressive and flexural strengths decreased in high rates. As the temperature increases more, the shrinkage that will occur with the loss of this water increases the strength of the concrete, and the vapor pressure that appears in the concrete may cause the concrete cover to crack and break off. Another component in the cement paste next to $\mathrm{C}-\mathrm{S}-\mathrm{H}$ is $\mathrm{Ca}(\mathrm{OH}) 2$ (calcium hydroxide). The chemical water and gel water of C-S-H start to disappear from $300{ }^{\circ} \mathrm{C}$ and turn into $\mathrm{CaO}$ by losing $\mathrm{Ca}(\mathrm{OH})_{2}$ water around $530{ }^{\circ} \mathrm{C}$ (Khoury 1996). Damages occurring at some temperatures cause the strength of concrete to decrease significantly (Poon et al. 2001).The flexural and compressive strength losses occurring in the reference sample for all temperatures are higher than the mortars that have mineral additives in mixture. It has been observed that with the use of mineral additives, mechanical losses caused by high temperature are reduced. When the compressive strengths are examined, a $78.68 \%$ reduction in compressive strength is observed in the reference sample with the temperature rising to $800{ }^{\circ} \mathrm{C}$. The lowest compressive strength loss in FA mineral admixed mortars is $61.34 \%$ in FA use, $20 \%$ in BFS mineral admixture mortars, $57.87 \%$ in BFS use, $1 \%$ in $\mathrm{K}$ mineral admixture mortars, $60.26 \%$ in $\mathrm{K}$ use, and MP mineral admixture $63.2 \%$ of the mortars are used in $10 \% \mathrm{MP}$ usage.

When the flexural strengths are examined, a $75.14 \%$ reduction in the compressive strength is observed with the temperature rising to $800{ }^{\circ} \mathrm{C}$ in the reference sample. The lowest flexural strength loss in FA mineral admixed mortars is $69.04 \%$ in $20 \%$ FA use, $20 \%$ in BFS mineral admixed mortars, $67.87 \%$ in BFS used, $61.9 \%$ in $1 \%$ use with $\mathrm{K}$ mineral admixture mortars, $61.9 \%$ in MP used and 
$56.2 \%$ occurred when the mortars are used in 10\% MP used. It is observed that $20.81 \%$ decrease in flexural strength and $21.77 \%$ decrease in flexural strength occurred with the use of mineral additives. It has been observed that the use of mineral additives increases the resistance of mortars to high temperature.

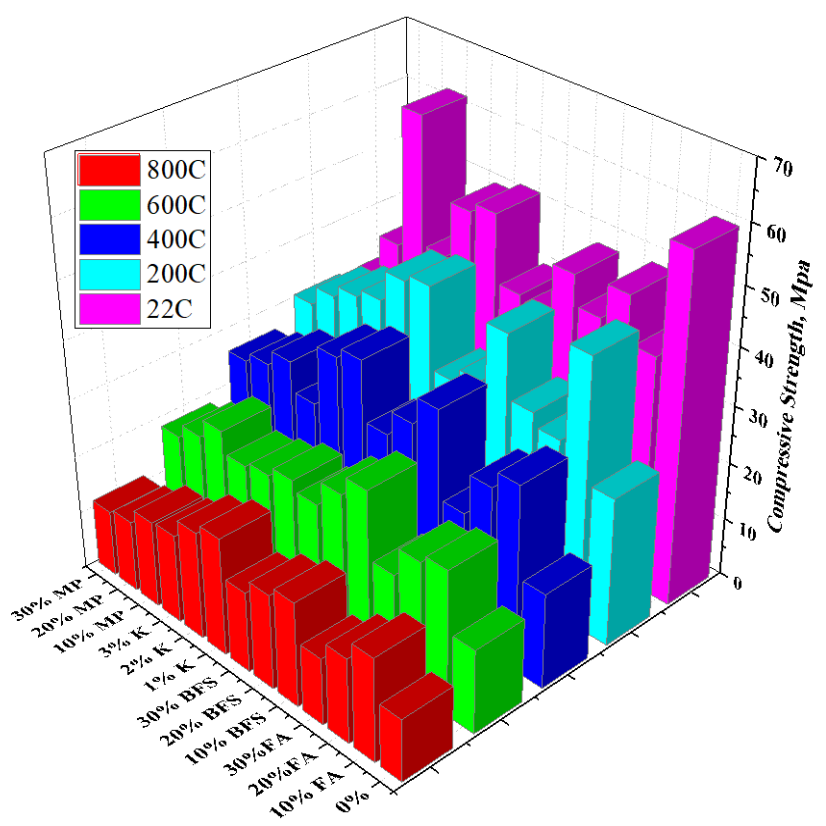

Figure 6. Compressive strengths before and after high temperature (MPa)

\section{CONCLUSION}

- A decrease in water absorption and porosity rates was observed in $30 \%$ of all mineral additives and in all ratios of $\mathrm{K}$.

- The lowest water absorption value was obtained with the use of $\% 30$ BFS with a ratio of 5,91\% and the highest water absorption with the use of $10 \% \mathrm{MP}$ with a ratio of $11,97 \%$.

- The lowest porosity value was obtained with the use of $10 \%$ BFS with $11,97 \%$ and the highest porosity with the use of $\% 10 \mathrm{MP}$ with $17,30 \%$.

- With the increase of mineral additives in the mortar, the amount of fine material increases. The need for water increases as the surface area increases with the increase of the fine substance. Settlement difficulties due to the need for water reveals difficulties and causes it to settle more porous, in this case, it causes an increase in water absorption and porosity values.

- With the increase in the ratio of mineral additives, there was a general decrease in compressive and flexural strengths. However, when using MPE rate increase in the compressive strength observed at $10 \%$, it was observed with increasing reduction rate of the MPA.

- 7-day flexural strength was observed in the sample with the highest 6,99 $\mathrm{MPa}$ and 10\% FA, while the lowest was $4.76 \mathrm{MPa}$ and $30 \% \mathrm{MP}$. The 28-day flexural strength was observed in the sample with the highest $8.99 \mathrm{MPa}$ and $1 \% \mathrm{~K}$, while the lowest was $5.79 \mathrm{MPa}$ and $30 \% \mathrm{MP}$.
- It was observed that weight losses increased with increasing temperature. With the use of mineral additives, it is observed that weight losses decrease after temperature. The highest weight loss reference sample is seen for all temperatures.

- $\quad$ The lowest weight losses in mortars with 10\% MP with a value of $1.14 \%$ at $200{ }^{\circ} \mathrm{C}$, with a value of $2.34 \%$ at $400{ }^{\circ} \mathrm{C}$ and $30 \%$ with MP additive, $3 \%$ at $600{ }^{\circ} \mathrm{C}$ with a value of $2.83 \%$ It was observed in mortars with $30 \%$ MP additives with a value of $7.40 \%$ at 800 ${ }^{0} \mathrm{C}$.

- With the increase of temperature, high rates of compressive and flexural strengths decreased. The flexural and compressive strength losses occurring in the reference sample for all temperatures are higher than the mortars that have in mineral additives in mixture. It has been observed that with the use of mineral additives, mechanical losses caused by high temperature are reduced.

- It is observed that with increasing temperature, weight loss increases, flexural and compressive strengths decrease in all samples. With the use of mineral additives, it was observed that both the weight losses and the losses in flexural and compressive strengths decreased and the mortars became more resistant to high temperature.

\section{REFERENCES}

Akca A H \& Özyurt N (2018). Effects of re-curing on microstructure of concrete after high temperature exposure. Construction and Building Materials, 168, 431-441. DOI: 10.1016/j.conbuildmat.2018.02.122

Andrew R M (2018). Global $\mathrm{CO}_{2}$ emissions from cement production. Earth System Science Data, 10(1), 195217. DOI: $10.5194 /$ essd-10-195-2018

Arioz $O$ (2007). Effects of elevated temperatures on properties of concrete. Fire Safety Journal, 42(8), 516-522. DOI: 10.1016/j.firesaf.2007.01.003

Aydin S \& Baradan B (2007). Effect of pumice and fly ash incorporation on high temperature resistance of cement based mortars. Cement and Concrete Research, 37(6), 988-995. DOI: 10.1016/j.cemconres.2007.02.005

Dimitriou G, Savva P \& Petrou M F (2018). Enhancing mechanical and durability properties of recycled aggregate concrete. Construction and Building Materials, 158, 228-235. DOI: 10.1016/j.conbuildmat.2017.09.137

Gawin D, Pesavento F \& Schrefler A (2004). Modelling of deformations of high strength concrete at elevated temperatures. Materials and Structures, 37, 218236.

Heikal M, El-Didamony H, Sokkary T M \& Ahmed I A (2013). Behavior of composite cement pastes containing microsilica and fly ash at elevated temperature. Construction and Building Materials, 38, 1180-1190. DOI: 10.1016/j.conbuildmat.2012.09.069

Huseien G F, Sam A R M, Shah K W, Mirza J \& Tahir M M (2019). Evaluation of alkaliactivated mortars containing high volume waste ceramic powder and fly ash replacing GBFS. Construction and Building 
Materials, 210, 78-92. DOI: 10.1016/j.conbuildmat.2019.03.194

Juan-Valdés A, Rodríguez-Robles D, García-González J, Guerra-Romero M I, Morán-del Pozo J M (2018). Mechanical and microstructural characterization of nonstructural precast concrete made with recycled mixed ceramic aggregates from construction and demolition wastes. Journal of Cleaner Production, 180, 482-493. DOI: 10.1016/j.jclepro.2018.01.191

Kermeli K, Edelenbosch 0 Y, Crijns-Graus W, Van Ruijven B J, Mima S, Van Vuuren D P \& Worrell E (2019). The scope for better industry representation in longterm energy models: modeling the cement industry. Applied Energy, 240, 964-985. DOI: 10.1016/j.apenergy.2019.01.252

Khaliq W \& Khan H A (2015). High temperature material properties of calcium aluminate cement concrete. Construction and Building Materials, 94, 475-487. DOI: 10.1016/j.conbuildmat.2015.07.023

Khoury G A (1996). Performance of Heated ConcreteMechanical Properties. Contract NUC/56/3604A with Nuclear Installations Inspectorate, Imperial College, London, United Kingdom, August.

Li L, Wang Q, Zhang G, Shi L, Dong J, Jia P (2018). A method of detecting the cracks of concrete undergo high-temperature. Construction and Building Materials, 162, 345-358. DOI: 10.1016/j.conbuildmat.2017.12.010

Liang X, Wu C, Su Y, Chen Z \& Li Z (2018). Development of ultra-high performance concrete with high fire resistance", Construction and Building Materials, 179, 400-412. DOI: 10.1016/j.conbuildmat.2018.05.241

Lin W M, Lin T D \& Powers L J (1996). Microstructures of fire-damaged concrete. ACI Materials Journal, 93(3), 199-205.

Mendes A, Sanjayan J G \& Collins F (2011). Effects of slag and cooling method on the progressive deterioration of concrete after exposure to elevated temperatures as in a fire event. Materials and Structures, 44, 709-718. DOI: $10.1617 /$ s11527-0109660-2

Mohammadhosseini H, Tahir M M \& Sam A R M (2018). The feasibility of improving impact resistance and strength properties of sustainable concrete composites by adding waste metalized plastic fibres. Construction and Building Materials, 169, 223-236. DOI: 10.1016/j.conbuildmat.2018.02.210

Pan Z, Tao Z, Cao Y F, Wuhrer R \& Murphy T (2018). Compressive strength and microstructure of alkali- activated fly ash/slag binders at high temperature. Cement and Concrete Composites, 86, 9-18. DOI: 10.1016/j.cemconcomp.2017.09.011

Poon C S, Azhar S, Anson M \& Wong Y L (2001). Comparison of the strength and durability performance of normal- and high-strength pozzolanic concretes at elevated temperatures. Cement and Concrete Research, 31(9), 1291-1300. DOI: 10.1016/S0008-8846(01)00580-4

Seshu D R \& Pratusha A (2013). Study on compressive strength behaviour of normal concrete and selfcompacting concrete subjected to elevated temperatures. Magazine of Concrete Research, 65(7), 415-421. DOI: 10.1680/macr.12.00108

Tam V W Y, Soomro M \& Evangelista A C J (2018). “A review of recycled aggregate in concrete applications (2000-2017). Construction and Building Materials, 172, 272-292. DOI: 10.1016/j.conbuildmat.2018.03.240

TS EN 1008 (2003). Mixing water for concrete Specifications for sampling, testing and assessing the suitability of water, including water recovered from processes in the concrete industry, as mixing water for concrete. Turkish Standard Institute, Ankara Turkey.

TS EN 1170-6 (1999). Precast concrete products-test method for glass fibre reinforced cement-part 6: determination of the absorption of water by immersion and determination of the dry density. Turkish Standard Institute, Ankara, Turkey.

TS EN 12390-4 (2002). Testing hardened concrete - Part 4: Compressive strength - Specification for testing machines. Turkish Standard Institute, Ankara, Turkey.

TS EN 13501-1+A1 (2019). Fire classification of construction products and building elements - Part 1: Classification using data from reaction to fire tests. Turkish Standard Institute, Ankara, Turkey.

TS EN 196-1 (2016). Methods of testing cement - Part 1: Determination of strength. Turkish Standard Institute, Ankara, Turkey.

TS EN 197-1 (2012). Cement- Stage 1: General cementscomponent. Turkish Standard Institute, Ankara Turkey.

Yaşar E \& Erdoğan Y (2005). Investigation of Engineering Properties of Building Materials Made With Acidic and Alcaline Pumic. Turkey 19. Uluslararant Mining Congress and Expo, 409-413.

(C) Author(s) 2021.

This work is distributed under https://creativecommons.org/licenses/by-sa/4.0/ 